\title{
Comparison of pore characteristics in the coal and shale reservoirs of Taiyuan Formation, Qinshui Basin, China
}

\author{
Yu Liu ${ }^{1,2} \cdot$ Yanming Zhu ${ }^{1,2}$
}

Received: 25 September 2015/Revised: 11 April 2016/Accepted: 4 May 2016/Published online: 20 August 2016

(C) The Author(s) 2016. This article is published with open access at Springerlink.com

\begin{abstract}
Coal and shale are both unconventional gas reservoirs. Comparison of pore characteristics in shale and coal would help understand organic pore structure in shale and investigate co-exploration of shale gas and coalbed methane in coal bearing strata. In this study, five shale samples and three coal samples of Taiyuan Formation were collected from Qinshui Basin, China. High pressure mercury injection, scanning electronic microscopy, and fractal theory have been used to compare pore characteristics in shale and coal. The results show that pore volumes in coal are much larger than that in shale, especially pores 3-100 nm. In coal, there are many semi-closed pores in micro pores $(<10 \mathrm{~nm})$ and transition pores $(10-100 \mathrm{~nm})$. On the contrary, micro pores and transition pores are mainly with open pores in shale. The fractal curves show that pores larger than $65 \mathrm{~nm}$ in coal and shale reservoir both have obvious self-similarity and the fractal dimension values in shale and coal are similar. But the fractal characteristics of pores smaller than $65 \mathrm{~nm}$ in shale reservoir are quite different from that in coal.
\end{abstract}

Keywords Comparison $\cdot$ Coal $\cdot$ Shale $\cdot$ Organic pores $\cdot$ Fractal

\section{Introduction}

Shale and coal seam are both unconventional gas reservoir for shale gas and coal bed methane. Shale gas and coalbed methane have the similar storage mechanism, and they are both mainly composed of free gas and adsorbed gas (Crosdale et al. 1998; Curtis 2002; Pan and Connell 2015; Pan and Wood 2015). Shale gas and coalbed methane are storied in pores, free gas staying in the center of pores and adsorbed gas adsorbed on the surface of pores (Zhang et al. 2012; Pan and Connell 2015). Pores in coal are all

Yu Liu

liuyu19901213@163.com

1 Key Laboratory of Coal Methane Resource \& Reservoir Formation Process of Ministry of Education, China University of Mining \& Technology, Xuzhou 221008, Jiangsu, China

2 School of Resource and Earth Science, China University of Mining \& Technology, Xuzhou 221116, Jiangsu, China organic pores, while pores in shale having different types such as organic pores, interparticle pores and intraparticle pores (Loucks et al. 2012). Among them, the organic pores have a great significance in storage of shale gas (Loucks et al. 2009). Also the methane adsorption of shale is controlled by the organic matter (Zhang et al. 2012). Pore system in shale is more complex than that of coal because shales have both organic pores and inorganic pores (Loucks et al. 2012). For the heterogeneity of shale, it is difficult to study the organic pores and inorganic pores respectively. By comparing pores in shale and coal, it would help understand the organic pores characteristics in shale. Also in the marine- terrestrial sedimentary environment, organic shale is usually adjacent to the coal in the vertical. In view of this, many scholars put forward the idea of co-exploration of shale gas and coalbed methane in coal bearing strata (Zou et al. 2010; Qin et al. 2014). It is necessary to study the differences and similarity of pores in shale and coal by comparing them.

Benefit from exploration and development of coalbed methane and shale gas, studies on the pores in shale and 
coal have attracted much attention. In recent years, there have been many achievements on pores of coal and shale reservoir and the pore size distribution, pore types, fractal characteristics have been understood (Yao and Liu 2012; Xue et al. 2012; Clarkson et al. 2013; Zhang et al. 2014; Wang et al. 2014; Dong et al. 2015; Okolo et al. 2015; Pan et al. 2015; Sakhaee-Pour and Bryant 2015; Xiong et al. 2015). Coal and shale both have a wide pore size range, from $\mathrm{nm}$ scale to $\mu \mathrm{m}$ scale (Wang et al. 2014; $\mathrm{Li}$ et al. 2015). High pressure mercury injection experiment is one of the most powerful methods to characterize the pore structure in both shale and coal (Okolo et al. 2015). Also, scanning electron microscope (SEM) experiment makes the pores in shale and coal visual and brings great help for studies of pores.

Recently, fractal is commonly used to investigate the pore structure and surface irregularities of shale and coal (Mahamud and Novo 2008; ; Zhang et al. 2011; Pan et al. 2016; Li et al. 2015; Sun et al. 2015; Yang et al. 2014). Fractal theory is primary used to study nonlinear and irregular characteristics of shapes (Xie 1996; Pan et al. 2016). Mercury porosimetry and gas adsorption methods are the common methods to investigate the fractal feathers of pore structure of coal and shale (Bu et al. 2015; Yang et al. 2014). The investigation results of fractal methods on coal and shale showed that fractal theory is an effective tool to study pores structure in shale and coal $(\mathrm{Bu}$ et al. 2015; Pan et al. 2016), and the methane adsorption capacity of shale also has relations with the fractal dimension (Pan et al. 2016).

Few previous studies were focused on the comparison of pores in shale and coal reservoir, but it would help understand the organic pores in shale and be necessary in the study of co-exploration of shale gas and coalbed methane in coal bearing strata. Besides, pore structure of marine- terrestrial shale has not been understood clearly. In this study, we collected coal and shale samples from the coal bearing strata in Qinshui Basin, China. High pressure mercury and fractal analysis have been used to compare the pore characteristic in coal and shale reservoir.

\section{Samples and experimental}

\subsection{Samples}

Five shale samples and three coal samples were chosen from Qinshui Basin in China in the study (Fig. 1). Qinshui Basin is located in the southeast of Shanxi Province and it is the most successful area for coalbed methane exploitation in China (Fig. 1). Qinshui Basin is a synclinore, in which fault is not developed.
The Taiyuan Formation coal and shale in Qinshui Basin are both formed in the marine-continental transitional environment and they have the same type of kerogen (III). But there is a big difference between coal and shale in the composition of the material content. Clay content is the highest in shale, with average of $52.4 \%$, followed by the quartz content. TOC of the shale is mainly within $1.5 \%$ $5.0 \%$. In coal, Organic matter is main component, and the content is above $90 \%$.

All of the shale samples are core samples and all of the coal samples were collected on the mining working face. The sample information is shown in Table 1 . The shale and coal samples are all in stage of maturity to over-maturity.

\subsection{Experiment}

\subsubsection{High pressure mercury injection experiment}

Because of the nonwetting between mercury and coal, pressure is needed to make mercury into pores. The higher the pressure is, the smaller of the pore size which the mercury could enter will be. So we can measure the amount of mercury of a certain pressure to get the volume of corresponding pore size. The model of high pressure mercury injection experimental instrument is Auto Pore IV 9500 V1.09.

As the upper limit of pressure value is $6000 \mathrm{psi}$, the lower limit value of the measured pore size is $3.0 \mathrm{~nm}$. The experimental samples are all the bulk samples, about $0.1-1 \mathrm{~cm}^{3}$ in size. The quality of coal samples is $1.5-2.5 \mathrm{~g}$, that of shale samples being 3-4 g. Samples need to be dried at $70{ }^{\circ} \mathrm{C}$ for more than $5 \mathrm{~h}$ before the experiment.

\subsubsection{Scanning electron microscope (SEM)}

Coal and shale samples for scanning electron microscope experiment are bulk samples. The SEM experiment was performed in Chinese University of Petroleum (Beijing). The experimental instrument is FEI Quanta 200. Some of the shale samples are polished by focused ion beam (FIBSEM), while coal and some shale samples are not. Samples have been prepared by gold spray treatment before the experiment. When observing under scanning electron microscope, energy dispersive spectrometer (EDS) has been combined to judge the pore types.

\subsubsection{Pore classification}

In this study, we used the classification classified by $\mathrm{Fu}$ (2001): micropores $<10 \mathrm{~nm}$, transition pore being $10-100 \mathrm{~nm}$, mesopores being $100-1000 \mathrm{~nm}$, macropores are larger than $1000 \mathrm{~nm}$. 

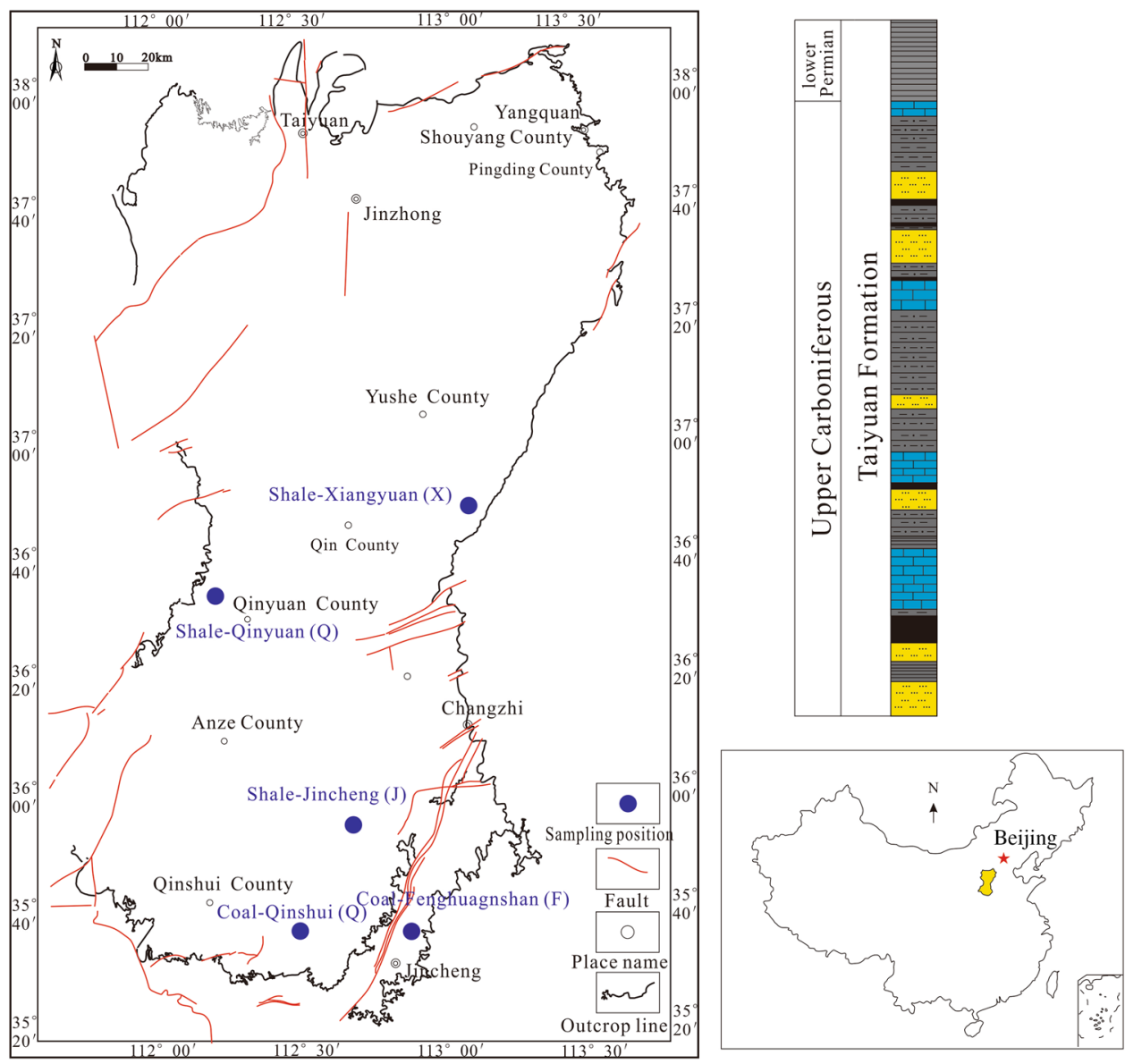

Fig. 1 The sampling position and the typical stratum histogram of Taiyuan Formation in Qinshui

Table 1 Sample information

\begin{tabular}{|c|c|c|c|c|c|c|}
\hline Sample number & Lithology & TOC $(\%)$ & Ro & Kerogen type & Clay content $(\%)$ & Quartz content $(\%)$ \\
\hline $\mathrm{J}-1$ & Shale & 3.44 & 2.92 & III & 51 & 29 \\
\hline Q-1 & Shale & 1.72 & - & III & 58 & 30 \\
\hline Q-2 & Shale & 2.12 & 1.72 & III & 43 & 30 \\
\hline $\mathrm{X}-1$ & Shale & 3.84 & 1.91 & III & 47 & 28 \\
\hline $\mathrm{X}-2$ & Shale & 2.58 & - & III & - & - \\
\hline F-1 & Coal & - & 3.3 (Liu 2007) & III & - & - \\
\hline $\mathrm{F}-2$ & Coal & - & 3.3 (Liu 2007) & III & - & - \\
\hline Q-1 & Coal & - & $2.4-2.8$ & III & - & - \\
\hline
\end{tabular}

Note The reflectance of vitrinite in coal sample Q-1 is from region data

\section{Results and discussion}

The high pressure mercury injection experimental results show that the porosity of coal samples in Qinshui Basin is $5.76 \%$ on average, significantly larger than that of shale samples (1.65\%) (Table 2). Coal reservoir and shale reservoir of Taiyuan Formation in Qinshui Basin are both mainly with pores smaller than $100 \mathrm{~nm}$ (Fig. 2). Pores whose throat is $1000-10,000 \mathrm{~nm}$ are not developed in shale and coal reservoir. Mesopores $(100-1000 \mathrm{~nm}$ ) is well developed in coal reservoirs, but these pores are not developed in shale. Figure 2 also shows that in the stage of $3-100 \mathrm{~nm}$, the number of pores in coal is significantly larger than that in shale. That is because organic pores are 
Table 2 Data of high pressure mercury injection of shale and coal

\begin{tabular}{lllllcc}
\hline $\begin{array}{l}\text { Sample } \\
\text { number }\end{array}$ & Lithology & $\begin{array}{l}\text { Porosity } \\
(\%)\end{array}$ & $\begin{array}{l}\text { Volume } \\
(\mathrm{mL} / \mathrm{g})\end{array}$ & $\begin{array}{l}\text { Specific area } \\
\left(\mathrm{m}^{2}\right)\end{array}$ & $\begin{array}{l}\text { Median pore } \\
\text { diameter (volume) }(\mathrm{nm})\end{array}$ & $\begin{array}{l}\text { Average pore } \\
\text { diameter }(\mathrm{nm})\end{array}$ \\
\hline F-1 & Coal & 4.66 & 0.04 & 19.67 & 7.5 & 7.2 \\
F-2 & Coal & 6.84 & 0.06 & 27.29 & 9.2 & 8.1 \\
Q-1 & Coal & 5.79 & 0.05 & 23.09 & 10 & 8.4 \\
J-1 & Shale & 1.88 & 0.01 & 2.38 & 191.1 & 13 \\
Q-1 & Shale & 1.74 & 0.01 & 3.2 & 13.6 & 10.2 \\
Q-2 & Shale & 1.17 & 0.01 & 1.55 & 7.9 & 13.7 \\
X-1 & Shale & 2.41 & 0.01 & 6.03 & 16.4 & 7.7 \\
X-2 & Shale & 1.4 & 0.01 & 2.34 & 10.9 \\
\hline
\end{tabular}

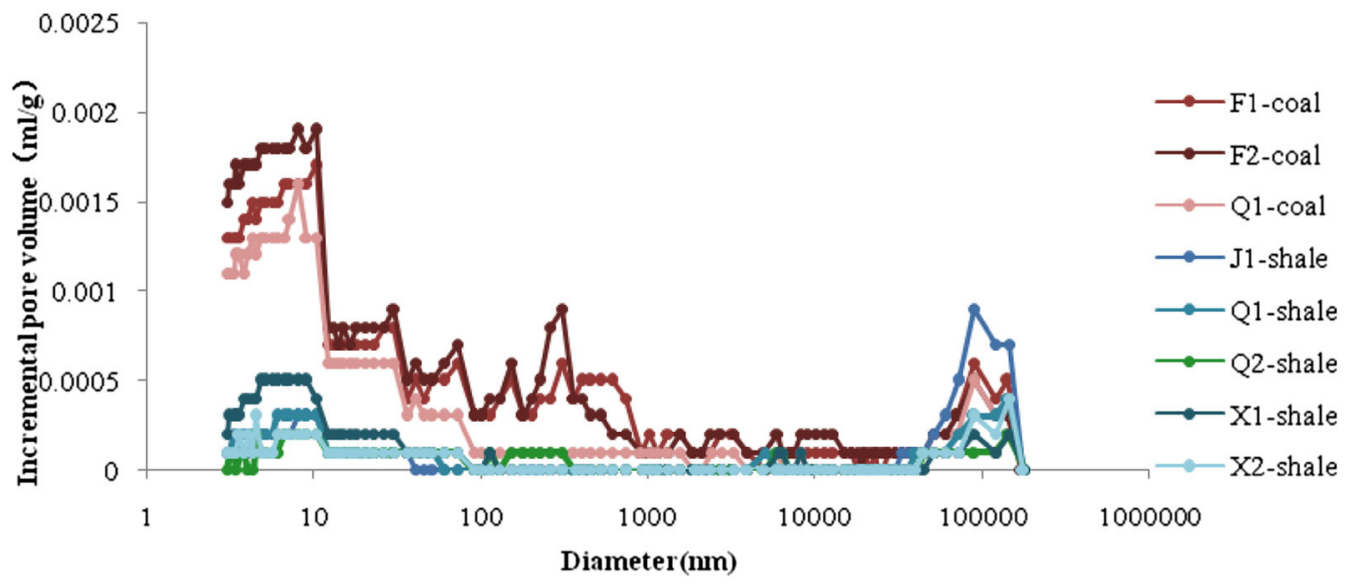

Fig. 2 Pore structure distribution of coal and shale in Qinshui Basin

mainly $3-100 \mathrm{~nm}$, and organic matter content in coal is much larger than that in shale. The increase of organic matter in coal brings much more organic pores, and these pores make the porosity of coal samples much larger than that of shale.

It should be noted that when testing the nanometer pores, the test pressure would become larger than $30 \mathrm{MPa}$ and the high pressure mercury injection experiment would overestimate the pore volume for the compressibility in coal and shale. Okolo et al. (2015) has studied effects of coal compressibility on the pore structure distribution from mercury injection experiment. It was showed that the pore volume would be overestimated by about $20 \%-25 \%$. Also, the pores could be damaged as the test pressure becomes larger than $30 \mathrm{MPa}$. The effects of damage in pore and compressibility are similar to coal and shale samples. Considering these factors, it is also clear that the pore volume of coal samples is much larger than that of shale samples, especially for pores smaller than $100 \mathrm{~nm}$.

Coal and shale have great differences in genetical types of pores. As the coal is the organ-enriched reservoir, absolute advantage of organic matter content makes that the pores in coal are mainly with organic pores. In the shale, clay, quartz and other minerals content accounted for the major. In the shale reservoir, pores larger than $100 \mathrm{~nm}$ are mainly mineral intergranular pores, solution pores and clay pores, and some organic pores (Fig. 3a, b, d).

The organic matter type and maturity in coal and shale of Taiyuan Formation in Qinshui Basin is similar. Large numbers of organic gas pores (mainly transition pores and micropores) exit in both the coal reservoir and shale reservoir. Those gas pores in coal and shale are very similar in pore size and shape (Fig. 3d, e, f, g). For the same quality of coal and shale, the content of organic matter in the coal reservoir is 20-30 times that in shale reservoir. Given the similarity of the gas pores in coal reservoir and shale reservoir, the porosity of the $3-100 \mathrm{~nm}$ organic pores in coal reservoir should be 20-30 times of organic pores in shale reservoir. But in fact, the total volume and surface area of 3-100 nm pores in coal reservoir is about 10 times of that in shale, and this reflects that there are certain amounts of inorganic pores in shale. By calculating, the 

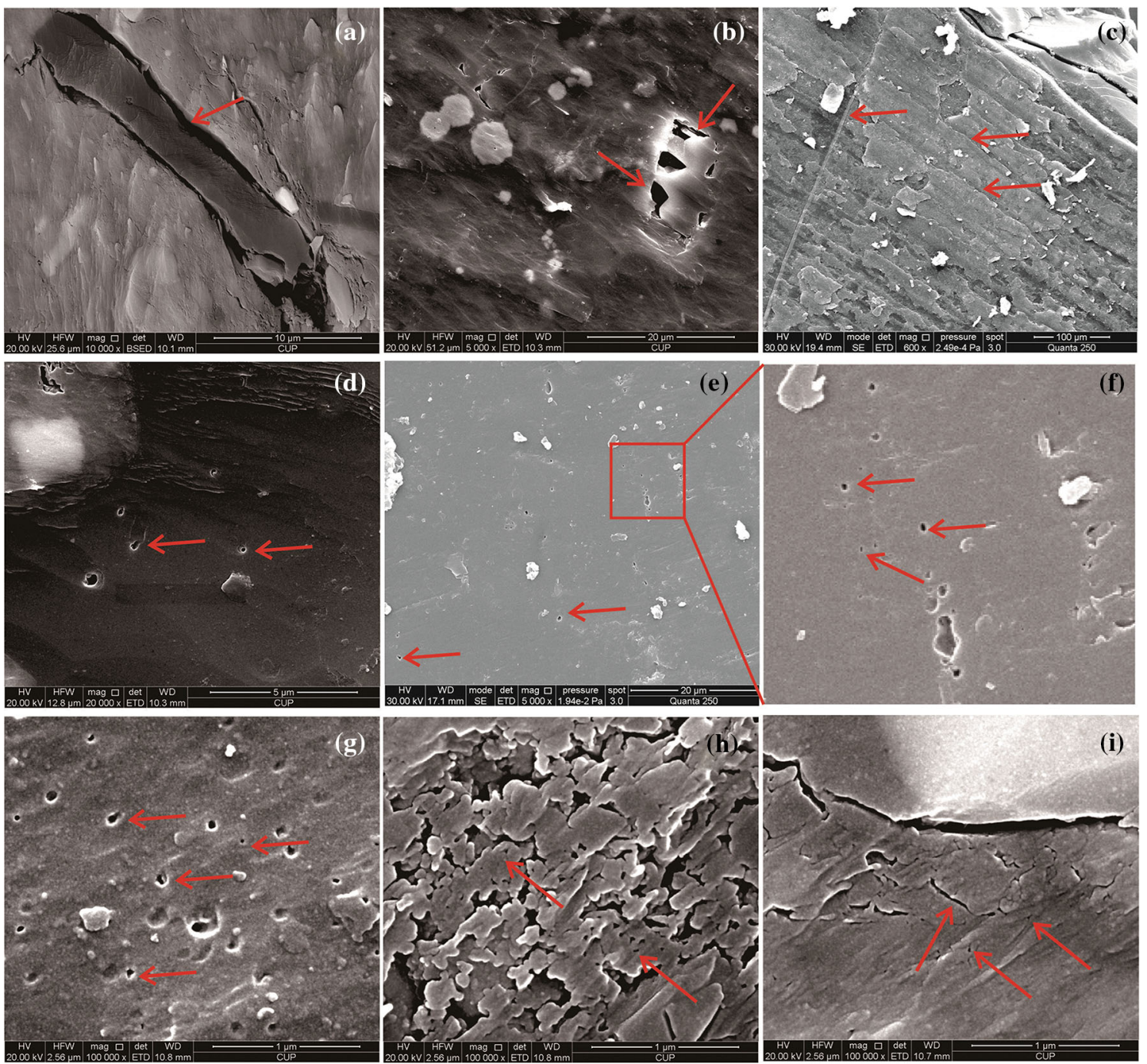

Fig. 3 Pore of shale reservoir in the Taiyuan Formation from Qinshui Basin. $a$ shale, FIB-SEM, intergranular pores. $b$ shale, FIB-SEM, mineral dissolution pores $c$ coal, SEM, cleats are well developed in the coal reservoir. $d$ shale, FIB-SEM, organic pores. $e$ coal, SEM, organic gas pores, familiar to organic pores in shale showed on d. $f$ coal, SEM, organic gas pores, magnified part of c. $g$ shale, FIB-SEM, organic pores, familiar to organic gas pores in coal reservoir showed on f. $h$ shale, FIB-SEM, clay pores. $i$ shale, FIB-SEM, clay pores

organic pores accounted for about $30 \%-50 \%$ of total 3-100 nm pores. Also we can observe many clay pores which are smaller than $100 \mathrm{~nm}$ by using SEM (Fig. 3h, i).

\subsection{Mercury injection curves and mercury withdrawal curves}

Mercury intrusion curves and mercury evacuation curves are often used in previous studies to reflect the pore shape of the pores in coal and shale reservoir (Chen et al. 2013; Qin 1994). Figures 4 and 5 show the mercury injection curves and mercury withdrawal curves of the coal and shale samples.

The pore morphology would control the mercury injection- mercury withdrawal curves of the pores
(Fig. 6). The differences in pore morphology of coal and shale samples would make the mercury injection-mercury withdrawal curves different. From Figs. 4 and 5, we can find that the mercury injection curves and mercury withdrawal curves of coal are quite different from that of shale, especially in the micro and transition pores stage. In micro and transition pores stage, mercury injection curve almost overlap mercury withdrawal curve in the coal reservoir, and this shows that there are a lot of semiclosed pres in the micro and transition pores (Qin 1994) (Fig. 6). But in the shale reservoir, the mercury injection curves are far from the mercury withdrawal curves (Fig. 5). At the beginning, the mercury injection curves show convex, and then have a sharp decline in $10 \mathrm{~nm}$ or so. It reflects that the pores at these stages in shale 

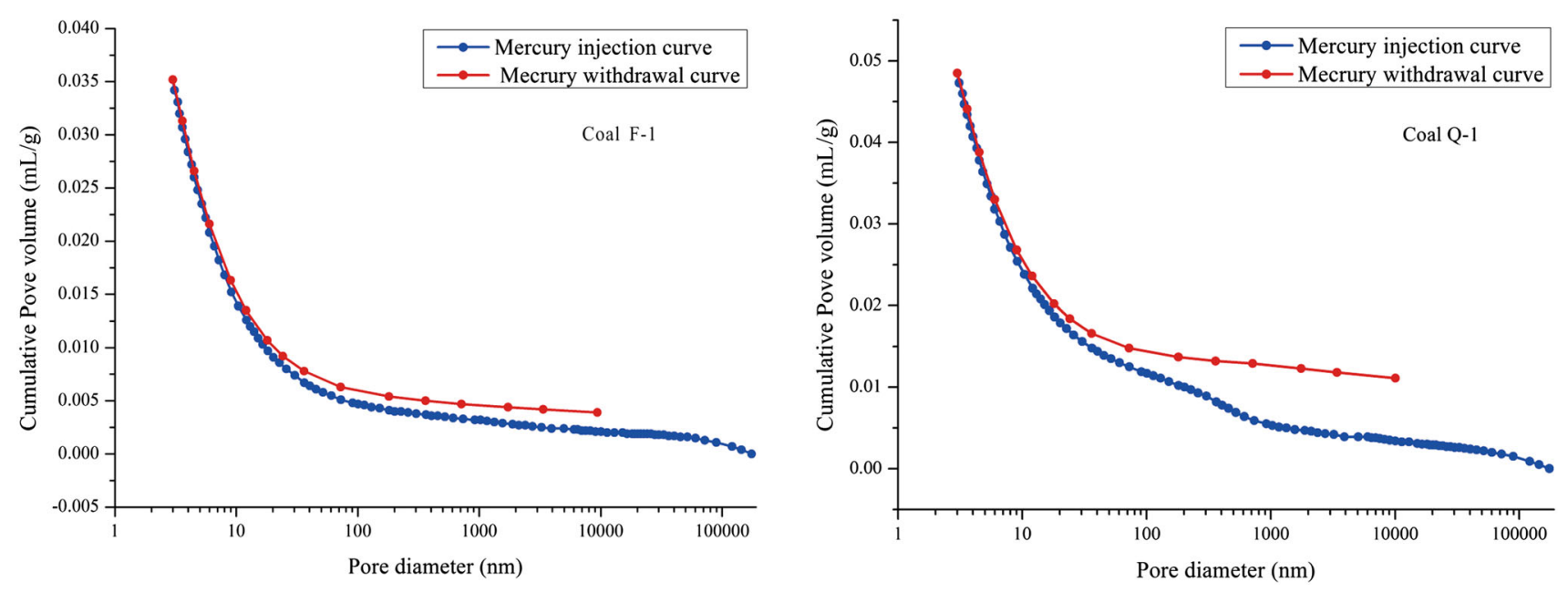

Fig. 4 Mercury injection curve and mercury withdrawal curve of coal samples
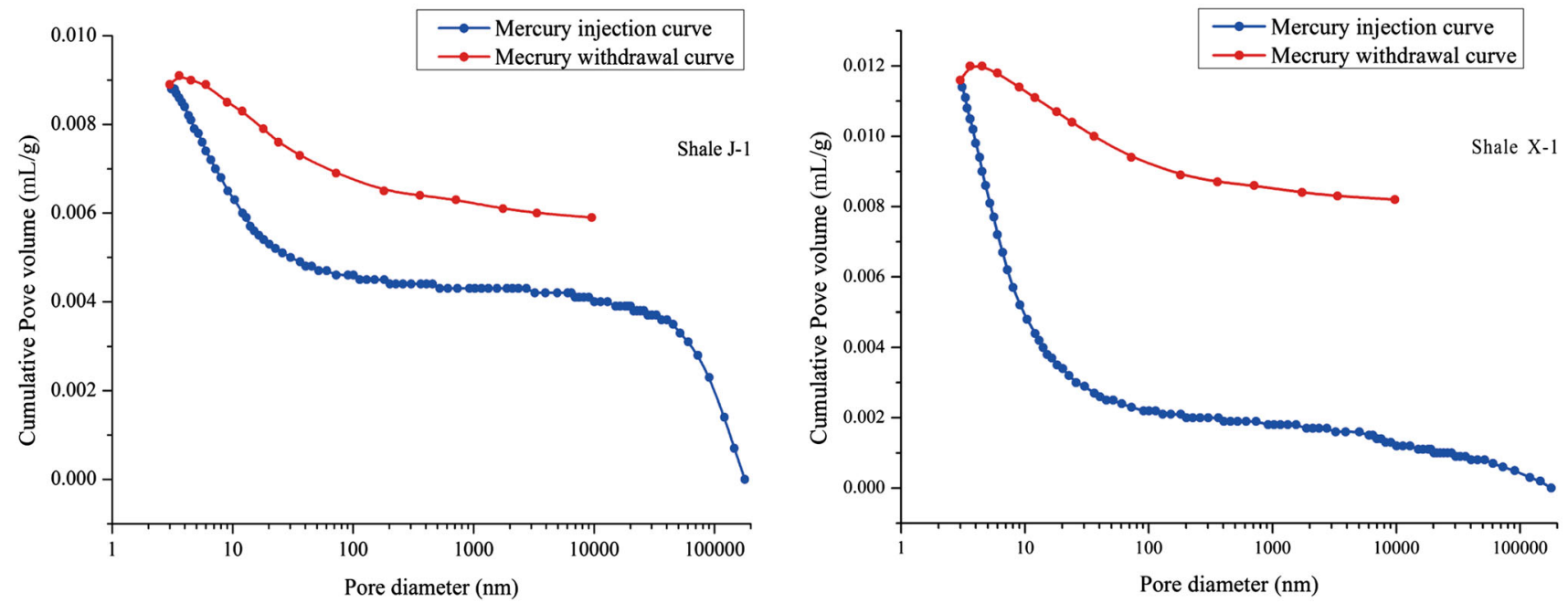

Fig. 5 Mercury injection curve and mercury withdrawal curve of shale samples

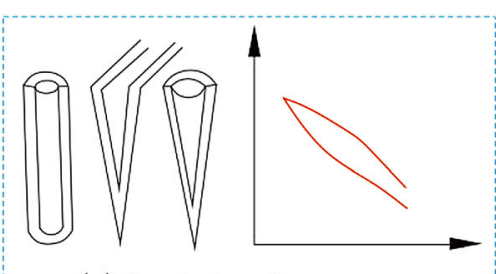

(a) Semi-closed pores
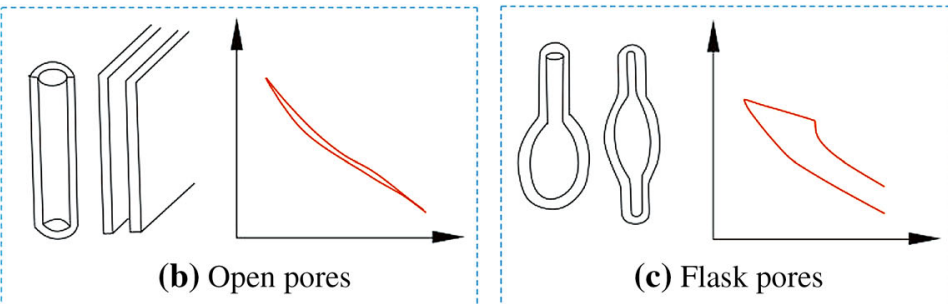

Fig. 6 Pore morphology and mercury injection-mercury withdrawal curves (Qin 1994)

reservoir are mainly open pores, and also have many "flask" pores around $10 \mathrm{~nm}$ (Qin 1994). At the stage of larger than $100 \mathrm{~nm}$, the mercury withdrawal curves of coal reservoir and shale reservoir all have certain distance from the mercury injection curves.

\subsection{Fractal characteristics of pores in coal and shale reservoir}

Coal and shale are both heterogeneous porous reservoir. For the heterogeneity of the shale and coal, fractal theory is 
introduced to study the pore characteristics of coal and shale (Mahamud and Novo 2008; Yang et al. 2014). In this study, high pressure mercury injection data of shale and coal samples was used to investigate the fractal features. The model used in the study is Menger sponge model, and the specific process of deduction and calculation are as follows (Xie 1996):

Assuming the length of initial element cube unit is $R$, divide the initial cube into $\mathrm{m}^{3}$ small same cubes, then select a rule to remove part of the small cubes, and the number of cubes left would be $N 1$; repeat the above operation on the smaller cubes. Then the side length of cubes decreases, and the cube number increases. After the operation for $K$ times, the side length of small cube $r=R / m k$, and the number of $N_{k}=N_{1} k$, at the same time:

$N_{k}=\left(R / r_{k}\right)^{D}=C_{1} / r_{k}^{D}=C_{1} r_{k}^{-D}$

There into:

$D=\lg N_{1} / \lg m, C_{1}$ is a Constant

$V_{k}=N_{k} C_{2} r_{k}^{3}=C_{1} C_{2} r_{k}^{3-D}$

In the mercury injection experiment, pressure $P(R)$ and aperture $r$ satisfy the Washburn equation (Eq. 4):

$P(r)=-2 \sigma \cos \theta / r$

In the formula, $\theta$ is mercury and solid medium contact angle (140 about) $\sigma$ is the surface tension of mercury $(0.48 \mathrm{~N} / \mathrm{m})$.In the mercury injection experiment, mercury injection volume under certain pressure $(d V P(R))$ is equal to the total pore volume $(V(k))$ at certain size:

$d V(k)=d V_{P(r)}$

$d V_{P(r)} / d P(r) \propto[r / P(r)] \cdot r^{2-D}$

$D=4+\lg \left(d V_{p} / d P(r)\right) / \lg (P(r))$

Through counting the mercury injection data for $d V p$ $(R) / d(P(R))$ and $d P(R), \lg (d V p(R) / P(R))-\lg (d P(R))$ diagram can be made, and the slope $(\mathrm{K})$ of the curve can be calculated, and then the pore fractal dimension $D$ would be obtained (Eq. (7)).
From Figs. 7 and 8 it could be found that the pore fractal curves of shale are similar to those of coal, and they all can be divided into two stages. But the boundary points of the two stages in shale and coal are different. The boundary points of coal reservoir fractal are in the interval of $54-85 \mathrm{~nm}$, with an average of $65 \mathrm{~nm}$, and that of shale reservoir pore fractal curve are smaller, $18-40 \mathrm{~nm}$, with an average of $28 \mathrm{~nm}$.

The pores larger than $65 \mathrm{~nm}$ in coal and shale reservoir both have obvious self-similarity: the degree of association between the pore fractal curves and the fitting line is larger than 0.9 . The fractal dimension values of pores in coal are 2.93-3.14, and fractal dimension values of pores in shale are 2.99-3.12. The fractal dimension values of shale are similar to that of coal, and this reflects that surface roughness of pores larger than $65 \mathrm{~nm}$ in both coal and shale is very similar.

Based on the fractal principle, the calculated fractal dimension for this model can't be larger than 3, but some calculated results shows the fractal dimensions are larger than 3. The reasons of these phenomena have been discussed in previous studies (An et al. 2011; Wang and He 1996). On the one hand, as the pores measured by mercury injection experiment are all connected pores, closed pores in the reservoir cannot be measured. But the fractal model used in the calculation (Menger sponge model) contains not only connected pores, but also closed pores. Thus the fractal dimension calculated by using the mercury injection data has slight deviations compared to the practical dimension. On the other hand, in the mercury injection experiments, with decrease of test aperture, the mercury pressure increases. In this case, smaller pores would be overestimated for the compressibility of coal and shale samples. As fractal dimension value is very close to 3, slight deviations would make the fractal dimension calculated larger than 3 .

The fractal characteristics of pores smaller than $65 \mathrm{~nm}$ in the coal reservoir are very different from that in shale reservoir. In the coal reservoirs, pores between 28 and $65 \mathrm{~nm}$ do not have self-similarity, but the self-similarity of
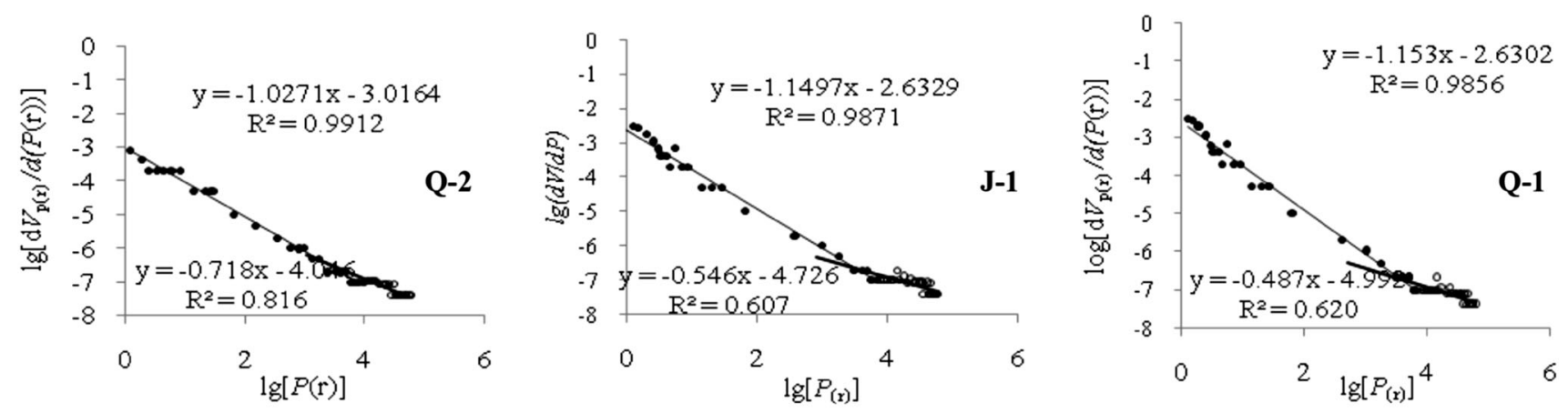

Fig. 7 Pore fractal curve of shale reservoir 

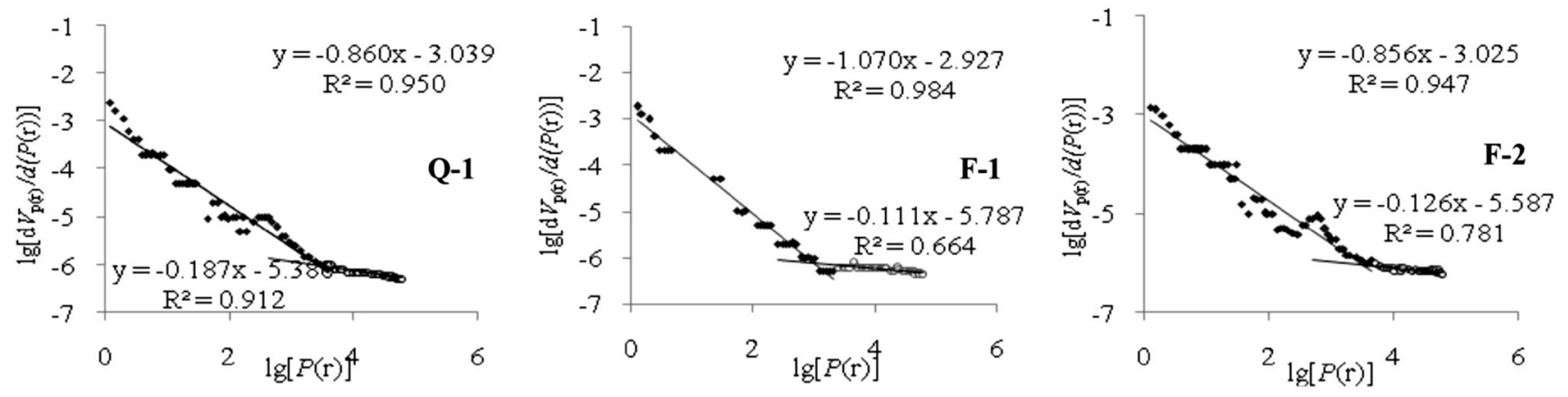

Fig. 8 Pore fractal curve of coal reservoir

shale pores in this stage is still obvious. This reflects that pores $28-65 \mathrm{~nm}$ in coal and shale reservoir have differences in shape. When the pore size is smaller than $28 \mathrm{~nm}$, the fractal curves of shale are similar to that of coal samples. The reasons are that although the pores of the $28-65 \mathrm{~nm}$ in shale reservoir have a lot of organic pores, but inorganic pores still occupies a large part of the total pores. With the decrease in pore size, the proportion of organic pores increases continuously. When the pores size is smaller than $28 \mathrm{~nm}$, pores in shale are mainly with organic pores, and the fractal curves of shale are similar to that of coal samples.

\section{Conclusions}

The porosity of coal samples from Qinshui Basin is $5.76 \%$ on average, and it is significantly larger than that of shale samples $(1.63 \%)$. Pore structure distribution of coal and shale samples show that pores smaller than $100 \mathrm{~nm}$ in coal are far more than that in shale.

Mercury injection curves and mercury withdrawal curves of shale samples are quite different from that of coal samples. In micro and transition pores stage, mercury injection curve almost overlap mercury withdrawal curve in the coal reservoir. There are a lot of semi closed pores in micro pores and transition pores in coal, but in shale micro pores and transition pores are mainly with open pores.

Pores larger than $65 \mathrm{~nm}$ in coal and shale reservoir have similar fractal dimension values. But the fractal characteristics of pores smaller than $65 \mathrm{~nm}$ in coal are different from that in shale. That is because inorganic pores still occupy part of the pores smaller than $65 \mathrm{~nm}$ in shale. With the decrease in pore size, the proportion of organic pores increases in shale. When the pores size is smaller than $28 \mathrm{~nm}$, pores in shale are mainly with organic pores, and the fractal curves of shale are similar to that of coal samples.
Acknowledgments The authors thank the National Science Foundation of China (41472135), the Research and Innovation Project for College Graduates of Jiangsu Province (KYLX15_1396), the Scientific Research Foundation of the Key Laboratory of Coalbed Methane Resources and Reservoir Formation Process, Ministry of Education (China University of Mining and Technology) (No. 2015-04) for the support of the research.

Open Access This article is distributed under the terms of the Creative Commons Attribution 4.0 International License (http://crea tivecommons.org/licenses/by/4.0/), which permits unrestricted use, distribution, and reproduction in any medium, provided you give appropriate credit to the original author(s) and the source, provide a link to the Creative Commons license, and indicate if changes were made.

\section{References}

An S, Sang S, Li Y, Wang G (2011) Study on pore fractal characteristics of high-rank coal reservoirs in Southern Qinshui Basin. Coal Geol China 23(2):17-21

Bu H, Ju Y, Tan J, Wang G, Li X (2015) Fractal characteristics of pores in non-marine shales from the Huainan coalfield, eastern China. J Nat Gas Sci Eng 24:166-177

Chen S, Xia X, Qin Y, Wang Y (2013) Classification of pore structures in shale gas reservoir at the Longmaxi Formation in the south of Sichuan Basin. J China Coal Soc 38(5):760-765

Clarkson CR et al (2013) Pore structure characterization of North American shale gas reservoirs using USANS/SANS, gas adsorption, and mercury intrusion. Fuel 103:606-616

Crosdale PJ, Beamish BB, Valix M (1998) Coalbed methane sorption related to coal composition. Int J Coal Geol 35:147-158

Curtis JB (2002) Fractured shale-gas systems. AAPG Bull 86(11): 1921

Dong Q, Zhang H, Zhu Z (2015) Evolution of structure properties during Zhundong coal pyrolysis. Procedia Eng 102:4-13

Fu X (2001) Physical simulation of multiphase medium coal rock properties and numerical simulation. University of Mining and Technology, Xuzhou

Li W, Liu H, Song X (2015) Multifractal analysis of Hg pore size distributions of tectonically deformed coals. Int $\mathrm{J}$ Coal Geol 144-145:138-152

Liu F (2007) The characteristics of coal reserviors and evaluation of coalbed methane enrichment and high-productivity in QinShui Basin of ShanXi Province. Chengdu University of Technology, Chengdu 
Loucks RG, Reed RM, Ruppel SC, Jarvie DM (2009) Morphology, genesis, and distribution of nanometer-scale pores in siliceous mudstones of the Mississippian Barnett Shale. J Sediment Res 79(12):848-861

Loucks RG, Reed RM, Ruppel SC, Hammes U (2012) Spectrum of pore types and networks in mudrocks and a descriptive classification for matrix-related mudrock pores. AAPG Bull 96(6):1071-1098

Mahamud MM, Novo MF (2008) The use of fractal analysis in the textural characterization of coals. Fuel 87(2):222-231

Okolo GN, Everson RC, Neomagus HWJP, Roberts MJ, Sakurovs R (2015) Comparing the porosity and surface areas of coal as measured by gas adsorption, mercury intrusion and SAXS techniques. Fuel 141:293-304

Pan Z, Connell LD (2015) Reservoir simulation of free and adsorbed gas production from shale. J Nat Gas Sci Eng 22:359-370

Pan Z, Wood DA (2015) Coalbed methane (CBM) exploration, reservoir characterisation, production, and modelling: a collection of published research (2009-2015). J Nat Gas Sci Eng 26:1472-1484

Pan J, Zhu H, Hou Q, Wang H, Wang S (2015) Macromolecular and pore structures of Chinese tectonically deformed coal studied by atomic force microscopy. Fuel 139:94-101

Pan J et al (2016) Micro-pores and fractures of coals analysed by field emission scanning electron microscopy and fractal theory. Fuel 164:277-285

Qin Y (1994) Micropetrology and structural evolution of high-bank coals in P.R.China. China University of Mining and Technology press, Beijing

Qin Y, Liang J, Shen J, Liu Y, Wang C (2014) Gas logging shows and gas reservoir types in tight sandstones and shales from Southern Qinshui Basin. J China Coal Soc 39(8):1559-1565

Sakhaee-Pour A, Bryant SL (2015) Pore structure of shale. Fuel 143:467-475

Sun W, Feng Y, Jiang C, Chu W (2015) Fractal characterization and methane adsorption features of coal particles taken from shallow and deep coalmine layers. Fuel 155:7-13
Wang E, He X (1996) Fractal desription of coal seam porosity and crack system and its application. J Fuxin Min Inst (Nat Sci) 15(4):407-410

Wang Y, Zhu Y, Chen S, Li W (2014) Characteristics of the nanoscale pore structure in Northwestern Hunan Shale gas reservoirs using field emission scanning electron microscopy, high-pressure mercury intrusion, and gas adsorption. Energy Fuels 28(2):945-955

Xie H (1996) Introduction to fractal petrology. Science Press, Beijing

Xiong J, Liu X, Liang L (2015) Experimental study on the pore structure characteristics of the Upper Ordovician Wufeng Formation shale in the southwest portion of the Sichuan Basin, China. J Nat Gas Sci Eng 22:530-539

Xue G, Liu H, Li W (2012) Deformed coal types and pore characteristics in Hancheng coalmines in Eastern Weibei coalfields. Int J Min Sci Technol 22(5):681-686

Yang F, Ning Z, Liu H (2014) Fractal characteristics of shales from a shale gas reservoir in the Sichuan Basin, China. Fuel 115:378-384

Yao Y, Liu D (2012) Comparison of low-field NMR and mercury intrusion porosimetry in characterizing pore size distributions of coals. Fuel 95:152-158

Zhang S, Yang S, Cheng J, Zhang B, Lu C (2011) Study on relationships between coal fractal characteristics and coal and gas outburst. Procedia Eng 26:327-334

Zhang T, Ellis GS, Ruppel SC, Milliken K, Yang R (2012) Effect of organic-matter type and thermal maturity on methane adsorption in shale-gas systems. Org Geochem 47:120-131

Zhang S, Tang S, Tang D, Huang W, Pan Z (2014) Determining fractal dimensions of coal pores by FHH model: problems and effects. J Nat Gas Sci Eng 21:929-939

Zou C, Dong D, Wang S, Li J (2010) Geological characteristics and resource potential of shale gas in China. Pet Explor Dev 37(6):641-653 